\title{
Neuroimaging of Hemorrhage and Vascular Defects
}

\author{
Fazeel M. Siddiqui, ${ }^{1,2}$ Simon V. Bekker, ${ }^{2,3}$ and Adnan I. Qureshi ${ }^{1,4}$ \\ ${ }^{I}$ Zeenat Queshi Stroke Research Center, University of Minnesota, Minneapolis, Minnesota; ${ }^{2}$ Southern Illinois University Health \\ Care, Springfield, Illinois; ${ }^{3}$ St-Johns Hospital, Springfield, Illinois; ${ }^{4}$ University of Minnesota, 12-100 PWB, 516 Delaware St. SE, \\ Minneapolis, Minnesota
}

\begin{abstract}
Summary: Intracranial hemorrhage is the third most common cause of stroke and involves the accumulation of blood within brain parenchyma or the surrounding meningeal spaces. Accurate identification of acute hemorrhage and correct characterization of the underlying pathology, such as tumor, vascular malformation, or infarction, is a critical step in planning appropriate therapy. Neuroimaging studies are required not only for diagnosis, but they also provide important information on the type of hemorrhage, etiology, and the pathophysiological process. Historically, computed tomography (CT) scan has been the diagnostic imaging study of choice; however, there is growing evidence suggesting that magnetic resonance imaging (MRI) is at least as sensitive as CT to detect intraparenchymal hemorrhages in the
\end{abstract}

hyperacute setting, and actually superior to CT in the subacute and chronic settings. Unique MRI and CT characteristics differentiate secondary causes of hemorrhage from the more common hypertensive hemorrhage. Baseline and serial studies can be used to identify patients who might benefit from acute interventions. In addition, new imaging modalities, (such as magnetic resonance spectroscopy, diffusion tensor imaging, and 320-row CT) are promising research techniques that have the potential to enhance our understanding of the tissue injury and recovery after intracranial hemorrhages. Key Words: Intracerebral hemorrhage, neuroimaging, vascular anomalies, cerebral angiopathy, computed tomography, magnetic resonance imaging.

\section{INTRODUCTION}

Intracranial hemorrhage ( $\mathrm{ICH})$ is the third most common cause of stroke (after ischemic and embolic strokes) and involves the accumulation of blood within brain parenchyma or the surrounding meningeal spaces [1]. Hemorrhage within the meninges or the associated potential spaces includes epidural hematoma (EDH), subdural hematoma (SDH), and subarachnoid hemorrhage (SAH). The etiology of ICH is multifactorial and varies with a person's age and predisposing factors (Table 1). This review will summarize the recent technical advances in neuroimaging ICH with respect to establishing a cause and therapeutic choices.

\section{ROLE OF NEUROIMAGING}

The major neuroimaging goal in suspected ICH is to identity hemorrhage with very high sensitivity and specificity. Accurate identification of acute ICH and

Electronic supplementary material The online version of this article (doi:10.1007/s13311-010-0009-x) contains supplementary material, which is available to authorized users.

Address correspondence and reprint requests to: Adnan I. Qureshi, University of Minnesota, 12-100 PWB, 516 Delaware St. SE, Minneapolis, MN. E-mail: qureshi@umn.edu. correct characterization of underlying pathology, such as tumor, vascular malformation, or infarction, is a critical step in planning appropriate therapy. Before the advent of recent imaging modalities, the diagnosis of ICH was based on clinical presentation and indirect angiographic findings. Confirmation could only occur after death [2]. The introduction of the computed tomography (CT) scan significantly altered the clinical approach to ICH by providing high diagnostic sensitivity for acute lesions [3]. This imaging procedure remains the standard in many institutions because it is readily available, applicable to almost any patient, and produces results which are relatively easy to interpret. However, as proton magnetic resonance imaging (MRI) becomes more readily available and as pulse sequences optimally sensitive to hemorrhage become standardized, the advantages of MRI over CT become more evident [4].

\section{CT scan}

The CT scan has traditionally been used in the diagnostic workup of ICH. There is a linear relationship between $\mathrm{CT}$ attenuation (hyperdensity) and hematocrit values. The attenuation of whole blood (hematocrit, $45 \%$ ) is $\sim 56$ Hounsfield units (HU), whereas the attenuation of normal gray matter ranges from 37 to 41 $\mathrm{HU}$, and normal white matter from 30 to $34 \mathrm{HU}$. Thus, a 
Table 1. Classification of Intracranial Hemorrhage

\begin{tabular}{|c|c|}
\hline Classification of intracranial hemorrhage & Pathophysiology \\
\hline Primary intraparenchymal hemorrhage & $\begin{array}{l}\text { Hypertensive; rupture of small arterioles related to degenerative } \\
\text { changes induced by uncontrolled hypertension [54]. }\end{array}$ \\
\hline \multicolumn{2}{|l|}{ Secondary intraparenchymal hemorrhage } \\
\hline Cerebral amyloid angiopathy & $\begin{array}{l}\text { Rupture of small and medium-sized arteries, with deposition of } \\
\beta \text {-amyloid protein; presents as lobar hemorrhages in persons } \\
\text { older than } 70 \text { years of age [54]. }\end{array}$ \\
\hline Hemorrhagic infarction & $\begin{array}{l}\text { Hemorrhage in region of cerebral infarction as a result of } \\
\text { ischemic damage to blood-brain barrier [54]. }\end{array}$ \\
\hline $\begin{array}{l}\text { Anticoagulation related hemorrhage } \\
\text { Intrinsic coagulation disorders }\end{array}$ & $\begin{array}{l}\text { Similar pathophysiology as primary intraparenchymal } \\
\text { hemorrhage; typically affects patients with vasculopathies } \\
\text { related to either chronic hypertension or cerebral amyloid } \\
\text { angiopathy, which might represent exacerbation of an existing } \\
\text { risk of clinical and subclinical disease [55]. }\end{array}$ \\
\hline $\begin{array}{l}\text { Substance abuse (cocaine, amphetamine, ecstasy, PCP, } \\
\text { decongestants and appetite suppressants) }\end{array}$ & Underlying vascular abnormalities may be present [54]. \\
\hline Infective endocarditis & $\begin{array}{l}\text { Secondary to formation of septic aneurysm, which is usually in } \\
\text { distal arterial branches [7]. }\end{array}$ \\
\hline Vasculitis & $\begin{array}{l}\text { Rupture of small or medium-sized arteries with inflammation } \\
\text { and degeneration [54]. }\end{array}$ \\
\hline Moyamoya syndrome & $\begin{array}{l}\text { Involves occlusion of major vessels with formation of collateral } \\
\text { vessels which are small, weak, and prone to hemorrhage, } \\
\text { aneurysm and thrombosis [56]. }\end{array}$ \\
\hline Cerebral venous sinus thrombosis & Result of hemorrhagic venous infarction [54]. \\
\hline Tumors & $\begin{array}{l}\text { Results of necrosis and bleeding within hypervascular } \\
\text { neoplasms [54]. }\end{array}$ \\
\hline Head trauma & Secondary to traumatic brain injury. \\
\hline Aneurysm & $\begin{array}{l}\text { Rupture of saccular dilatation from a medium-sized artery that is } \\
\text { usually associated with SAH [54]. }\end{array}$ \\
\hline Arteriovenous malformation & $\begin{array}{l}\text { Rupture of abnormal small vessels connecting arteries and } \\
\text { veins [54]. }\end{array}$ \\
\hline Venous angioma & Rupture of abnormal dilatation of venules [54]. \\
\hline Cavernous angioma & $\begin{array}{l}\text { Rupture of abnormal capillary-like vessels with intermingled } \\
\text { connective tissue [54]. }\end{array}$ \\
\hline $\begin{array}{l}\text { Subarachnoid hemorrhage } \\
\text { Aneurysm } \\
\text { Arteriovenous malformation } \\
\text { Non-aneurysmal perimesencephalic hemorrhage } \\
\text { Dural malformation } \\
\text { Trauma } \\
\text { Vascular dissection }\end{array}$ & $\begin{array}{l}\text { Similar pathophysiology as above with extension to } \\
\text { subarachnoid space. } \\
\text { Perimesencephalic non-aneurysmal subarachnoid haemorrhage } \\
\text { is a benign variant of unknown (probably venous) cause, with } \\
\text { the centre of bleeding most commonly located in the prepontine } \\
\text { cistern [19]. }\end{array}$ \\
\hline Subdural hemorrhage & Rupture of bridging veins [57]. \\
\hline Epidural hemorrhage & $\begin{array}{l}\text { Arterial EDHs usually result from laceration of branches of the } \\
\text { meningeal arteries, whereas venous EDHs result from a tear in } \\
\text { the dural venous sinuses [19]. }\end{array}$ \\
\hline
\end{tabular}

new ICH in a patient with normal hematocrit can be easily demonstrated on CT scan [5].

\section{Advantages and disadvantages of the CT scan} [5]. The CT scan is a rapid, relatively easy, noncumbersome imaging modality that is accurate in most regions of the brain in non-anemic patients. The disadvantages of this technique are:

- Since increased attenuation of whole blood is based primarily on the protein concentration of the blood (hemoglobin), hemorrhage associated with hemoglobin values $10 \mathrm{~g} / \mathrm{dl}$ may be undetectable based on density alone. Likewise, in infants with high hematocrit and in patients with polycythemia, the sinuses and vessels may appear abnormally dense.

- Lesions in the brain stem may be obscured by beam hardening artifact.

- Thin, flat collections of blood (particularly subarach- 
noid and extracerebral hemorrhages) may not be visualized because of partial volume averaging.

- The differential diagnosis of hemorrhagic infarction versus hemorrhagic tumor can be difficult.

- An enhancing ring in an uncomplicated ICH may appear from approximately 6 days to 6 weeks after the initial event and can be diagnostically challenging as the differential diagnosis of a ring-enhancing lesion may include tumor, abscess, infarction, and multiple sclerosis.

\section{Magnetic resonance imaging}

The CT scan has been widely considered to be the gold standard of modalities used to image brain hemorrhage because of the assumed low sensitivity of MRI for intracranial blood. However, the findings of the Hemorrhage and Early MRI Evaluation (HEME) study suggest that MRI may be as accurate as CT scan in detecting acute bleeding in the brain in patients showing signs of stroke, and actually more accurate than CT in revealing chronic bleeding in the brain, particularly microbleeds [4]. Researchers stopped the HEME study early after an interim analysis revealed that MRI had a higher sensitivity than CT for detecting ICH: in diagnosing any type of bleeding, MRI identified 71 patients with any grade of $\mathrm{ICH}$, while CT scan identified 29 patients with any grade of ICH. Acute ICH was diagnosed in 25 participants on both MRI and CT images, with four additional patients identified on MRI scans not found in the corresponding CT scan. Chronic bleeding, most often microbleeds, was visualized on 49 patients on the MRI scans, although not identified on corresponding CT scans. These findings complement another recently published study performed by the German Stroke Competence Network which suggest that MRI is as accurate as CT for the detection of hyperacute hemorrhage [6].

Goals of MRI in the evaluation of ICH. MRI localizes and differentiates ICHs into intra-axial (intraparenchymal and intraventricular) and extra-axial hemorrhage (SAH, SDH, and $\mathrm{EDH})$. In the case of intraaxial hemorrhage, the multi-planar display of MRI helps to accurately locate the specific neuro-anatomic site [2, 7]. The oxidation state of iron within hemoglobin changes as the molecules complete their transformation from intracellular oxygenated hemoglobin to hemosiderin. These various oxidation states of iron produce different signal intensities on MRI scans and allow the age of the hematoma to be estimated [7]. MRI also helps to identify the etiology, aids in the management, and provides information for prognostication [2].

\section{PATHOPHYSIOLOGY OF ICH}

There is a well-described pathophysiological process of evolution and resorption for ICH that involves five distinct phases: hyperacute $(<12 \mathrm{~h})$; acute $(12 \mathrm{~h}$ to 2 days); early subacute ( $2-7$ days); late subacute ( 8 days to 1 month); chronic ( $>1$ month to years). This process of evolution and resorption is directly or indirectly influenced by many factors, including the location of the hematoma, specific etiology, size, and a wide range of biological factors, including co-morbid diseases, general physique, medical treatment and interventions, hematocrit, and $\mathrm{pH}$ level [5, 7-9].

Hyperacute hematoma is a mixture of normal biconcave red blood cells (RBC), white blood cells, and platelets. Intracellular hemoglobin remains oxygenated during this stage. In the acute phase, RBCs lose their energy and shrink, but their membrane remains intact.

Table 2. Appearance of Blood on Computed Tomography and Magnetic Resonance Imaging Scans by Stage

\begin{tabular}{|c|c|c|c|c|}
\hline Stages & $\mathrm{CT}$ & T1-weighted MRI & T2-weighted MRI & GRE MRI \\
\hline Hyperacute $(<12$ h) & High density & $\begin{array}{l}\text { Isointense or } \\
\text { mildly hyperintense }\end{array}$ & Hyperintense & Hypointense rim \\
\hline Acute ( $12 \mathrm{~h}$ to 2 days) & High density & $\begin{array}{l}\text { Isointense or } \\
\text { hypointense }\end{array}$ & Hypointense & $\begin{array}{l}\text { Hypointense rim } \\
\text { that gradually } \\
\text { progresses to center }\end{array}$ \\
\hline Early subacute ( $2-7$ days) & High density & Hyperintense & Hypointense & Hypointense \\
\hline $\begin{array}{l}\text { Late subacute } \\
\text { ( } 8 \text { days to } 1 \text { month) }\end{array}$ & Isodense & Hyperintense & $\begin{array}{l}\text { Hyperintense } \\
\text { with rim of low } \\
\text { intensity }\end{array}$ & $\begin{array}{l}\text { Hyperintense with rim } \\
\text { of low intensity }\end{array}$ \\
\hline Chronic $(>1 \mathrm{~m})$ & Low density & Hypointense & Hypointense & $\begin{array}{l}\text { Slit-like hyperintense or } \\
\text { isointense core that is } \\
\text { surrounded by a } \\
\text { hypointense rim }\end{array}$ \\
\hline
\end{tabular}

$\mathrm{CT}=$ Computed tomography, MRI $=$ magnetic resonance imaging, $\mathrm{GRE}=$ gradient recalled echo

Reproduced with permission from Kidwell and Wintermark [19]. Copyright $(C)$ Elsevier. 
Table 3. Classification of Primary Intraparenchymal Hemorrhage [2]

\begin{tabular}{|c|c|c|c|}
\hline Type & Anatomic site & Arterial territory & Prognosis/comments \\
\hline Striatocapsular & & & \\
\hline Anterior & Caudate nucleus & Heubner's artery & Favorable prognosis \\
\hline Middle & $\begin{array}{l}\text { Globus pallidus or medial } \\
\text { putamen }\end{array}$ & Medial lenticulostriates & $\begin{array}{l}\text { Good prognosis, more than half } \\
\text { achieve functional independence }\end{array}$ \\
\hline Posteromedial & Posterior limb of IC & Anterior choroidal & \\
\hline Posterolateral & Posterior putamen & $\begin{array}{l}\text { Posteromedial branches of } \\
\text { lateral lenticulostriates }\end{array}$ & $\begin{array}{l}\text { Most common, functional recovery } \\
\text { limited because of persistent } \\
\text { hemiparesis }\end{array}$ \\
\hline Lateral & $\begin{array}{l}\text { External capsule, subinsular } \\
\text { region }\end{array}$ & $\begin{array}{l}\text { Lateral branches of lateral } \\
\text { lenticulostriates }\end{array}$ & Good functional recovery \\
\hline Massive & Entire area & Variable & Poor prognosis \\
\hline Lobar & Cortico-subcortical junction & Variable & $\begin{array}{l}\text { Secondary causes should be ruled } \\
\text { out; favorable prognosis, seizures } \\
\text { common. Presence of } \\
\text { hydrocephalus is relative indication } \\
\text { of surgical evacuation. Temporal } \\
\text { lobe hematomas may cause } \\
\text { herniation }\end{array}$ \\
\hline Thalamic & & & \\
\hline Anterior & $\begin{array}{l}\text { Anterior thalamus with/without } \\
\text { extension to anterior IC }\end{array}$ & $\begin{array}{l}\text { Polar or tuberothalamic } \\
\text { artery }\end{array}$ & Favorable prognosis \\
\hline Posteromedial & Medial thalamus & $\begin{array}{l}\text { Thalamo-subthalamic } \\
\text { paramedian artery }\end{array}$ & $\begin{array}{l}\text { Hematomas with mesencephalic } \\
\text { compromise and hydrocephalus } \\
\text { carry poor prognosis }\end{array}$ \\
\hline Posterolateral & $\begin{array}{l}\text { Posterior thalamus with } \\
\text { extension to posterior limb of } \\
\text { IC }\end{array}$ & Thalamogeniculate artery & Partial recovery, $30 \%$ mortality \\
\hline Dorsal & $\begin{array}{l}\text { Dorsal thalamus alongside of } \\
\text { lateral ventricle }\end{array}$ & Posterior choroidal & Favorable prognosis \\
\hline Global & Entire thalamus & Variable & Poor prognosis \\
\hline Cerebellar & $\begin{array}{l}\text { Cerebellar hemisphere } \\
\text { Vermian }\end{array}$ & $\begin{array}{l}\text { Superior cerebellar artery or } \\
\text { occasionally posterior } \\
\text { inferior cerebellar artery }\end{array}$ & $\begin{array}{l}\text { Serial imaging can be life saving. } \\
\text { Surgical evacuation recommended } \\
\text { for large hematoma }(>3 \mathrm{~cm}) \text {. } \\
\text { Poor prognosis }\end{array}$ \\
\hline Pontine & $\begin{array}{l}\text { Unilateral tegmental } \\
\text { Bilateral tegmental } \\
\text { Massive }\end{array}$ & $\begin{array}{l}\text { Paramedian or short } \\
\text { circumferential vessels }\end{array}$ & $\begin{array}{l}\text { Rule out cavernous angioma } \\
\text { Good prognosis } \\
\text { Poor prognosis } \\
\text { Extremely poor prognosis }\end{array}$ \\
\hline Intraventricular & & Variable & $\begin{array}{l}\text { Secondary causes should be ruled } \\
\text { out. Spontaneous intraventricular } \\
\text { hemorrhage carry better prognosis } \\
\text { for unclear reasons. }\end{array}$ \\
\hline
\end{tabular}

Key: IC=internal capsule; This table is modified with permission from 'Alejandro Rabinstein, Steven Resnick. Spontaneous Intraparenchymal Hemorrhage, In Practical Neuroimaging in Stroke-A Case Based Approach (pp. 229-258), Copyright Saunders an imprint of Elsevier Inc. (2009).

Intracellular hemoglobin starts deoxygenating during this phase. The subacute phase involves the transformation of deoxygenated hemoglobin into methemoglobin. Initially, the red cell membrane remains intact, leading to the accumulation of intracellular methemoglobin, but in the late subacute phase, the membrane is degraded, and methemoglobin is released into the extracellular space. The chronic phase involves the conversion of methemoglobin into hemosiderin and ferritin, which is stored in macrophages $[9,10]$. 


\section{MRI features and evolution of ICH}

The MRI appearance of hemorrhage is influenced by both the diamagnetic or paramagnetic properties of iron and the integrity of the RBC membrane. Diamagnetic substances do not have unpaired electrons in the atomic and molecular orbitals and, therefore, they reduce the magnitude of the magnetic field. On the contrary, paramagnetic substances have unpaired electrons, and they do augment an applied magnetic field when exposed to such a field [11].

Iron is diamagnetic when oxygenated and paramagnetic when deoxygenated [7]. In its paramagnetic state, it creates a dipole-dipole interaction that shortens the T1 and T2 relaxation times, with a greater effect on T1-weighted images than on T2-weighted images. As long as the RBC membrane remains intact, iron atoms are compartmentalized, which causes inhomogeneity of the magnetic field, loss of phase coherence, and shortening of $\mathrm{T} 2$ relaxation time, all of which cause a susceptibility effect. When the RBC membrane degrades, iron is evenly distributed between the intracellular and extracellular compartments, and this susceptibility effect is lost $[11,12]$.

Table 2 describes the evolution of hemorrhage on MRI and CT based on the degradation of hemoglobin and the diamagnetic and paramagnetic properties of its products.

\section{Intraparenchymal hemorrhage}

Intraparenchymal hemorrhage accounts for $8-15 \%$ of all strokes and is the most lethal form of stroke [13]. The mortality rate is almost $50 \%$ within the first month, and only $20 \%$ of the patients are able to live independently at 6 months from onset [14]. Rapid recognition and diagnosis are essential because of the frequently rapid progression during the first several hours of ictus [15]. Intraparenchymal hemorrhages are broadly classified into primary (spontaneous) and secondary intraparenchymal hemorrhage [2] Neuroimaging helps to accurately identify, localize, and predict etiology that eventually influences clinical decisionmaking. Serial MRI and CT scans can be helpful in identifying patients who can potentially benefit from acute neurosurgical interventions [2]. Various radiological features also predict functional outcome after intraparenchymal hemorrhage, including hematoma volume, midline shift, infratentorial location, intraventricular extension, and development of hydrocephalus [16, 17].
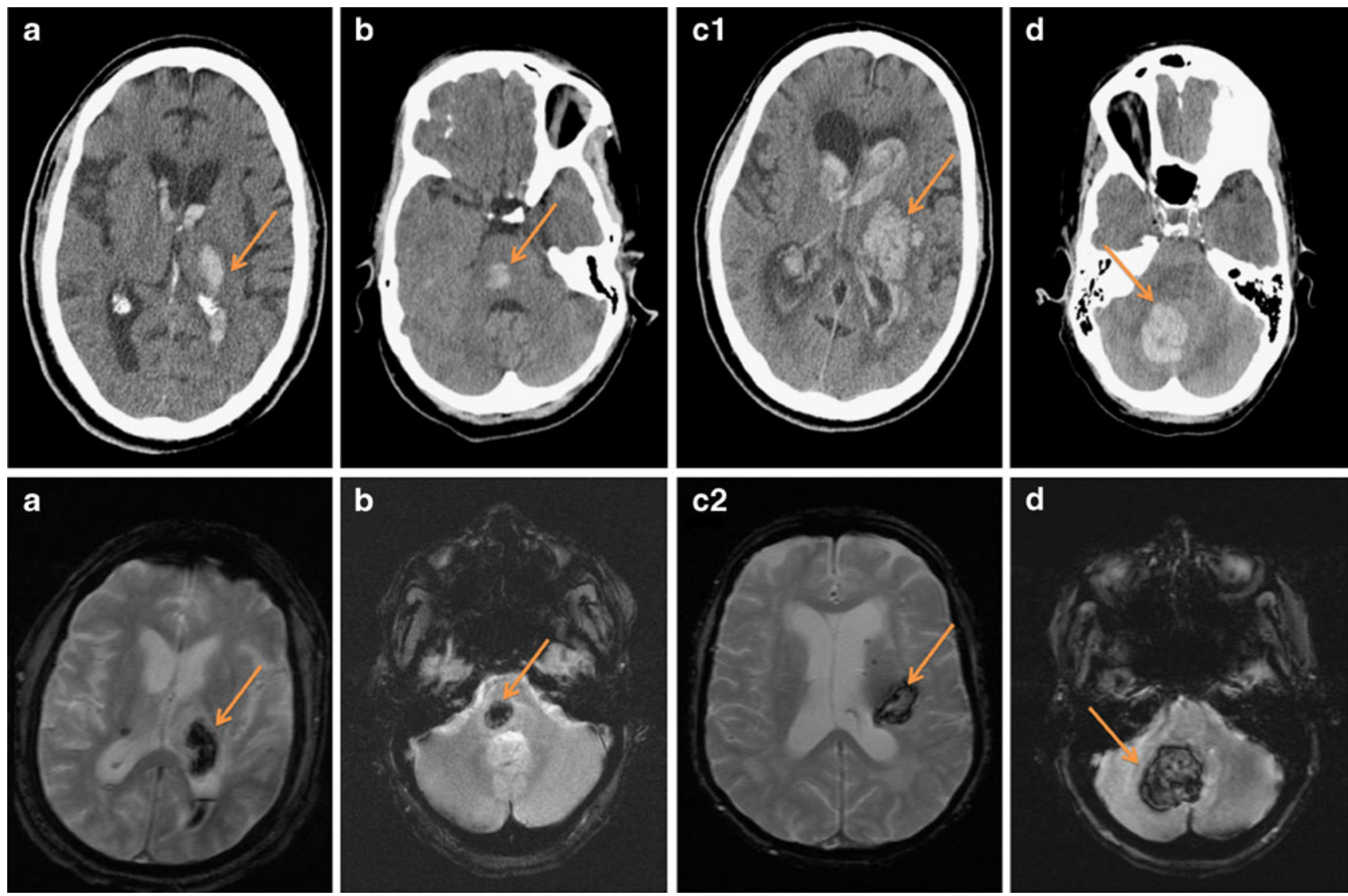

FIG. 1. Examples of primary intraparenchymal hemorrhage (arrows). (a) Left thalamic hemorrhage [imaging modality: computed tomography $(\mathrm{CT})$ and gradient recalled echo magnetic resonance imaging (GRE MRI)], (b) right pontine hemorrhage (CT and GRE), (c1) extensive basal ganglia hemorrhage with intraventricular extension (CT), (c2) putaminal hemorrhage (GRE), (d) right cerebellar hemorrhage (CT and GRE). (High resolution version of this image is available in the electronic supplementary material.) 
Primary intraparenchymal hemorrhage. Classification of primary intraparenchymal hemorrhage is typically based on the anatomic location. The most common sites $[2,18]$ of origin of primary intraparenchymal hemorrhage are:

1. Striatocapsular $(30-50 \%)$

2. Lobar $(20-40 \%)$

3. Thalamic $(10-20 \%)$

4. Cerebellar $(7-12 \%)$

5. Pontine $(2-8 \%)$

6. Intraventricular (1-3\%).

Table 3 describes the value of neuroimaging in the diagnostic assessment, clinical management, and prognostication of patients with primary intraparenchymal hemorrhage in each of these locations. All primary hemorrhages are secondary to hypertension, although some reviews included cerebral amyloid angiopathy as one of the causes of primary intracerebral hemorrhage [19]. FIG. 1 illustrates various examples of primary intraparenchymal hemorrhage.
Secondary intraparenchymal hemorrhage. Multiple factors other than chronic hypertension can cause intraparenchymal hemorrhage. The identification of underlying secondary etiologies is difficult in the acute setting, but it may be critical in some cases to avoid subsequent complications. Neuroimaging can be helpful for distinguishing secondary causes of hemorrhages, and certain neuroimaging features can identify patients at high likelihood of secondary causes. Table 4 describes various causes of secondary intraparenchymal hemorrhage and useful discriminating points on neuroimaging. FIG. 2 shows some examples of secondary intraparenchymal hemorrhage.

\section{Subarachnoid hemorrhage and intracranial aneurysm}

CT scan has been used to diagnose SAH since its availability. In addition to rupture of intracranial aneurysm, other causes of SAH include secondary leakage of blood from a primary intraparenchymal hemorrhage,

Table 4. Causes and Neuroimaging Characteristics of Secondary Intraparenchymal Hemorrhage [2, 7]

\begin{tabular}{|c|c|}
\hline Etiology & Neuroimaging characteristics \\
\hline Cerebral amyloid angiopathy & $\begin{array}{l}\text { Multiple hemorrhages of different ages involving parieto-occipital lobes } \\
\text { and characteristically sparing basal ganglia }\end{array}$ \\
\hline Hemorrhagic infarction & $\begin{array}{l}\text { Cortical hemorrhage within an arterial vascular territory. Non hemorrhagic } \\
\text { component shows diffusion restriction in DWI. There is an early contrast } \\
\text { enhancement due to disruption of BBB }\end{array}$ \\
\hline Anticoagulation related hemorrhage & $\begin{array}{l}\text { Characteristically shows multiple stages of hematoma in the same lesion } \\
\text { with a fluid level. Serial CTs show hematoma expansion. }\end{array}$ \\
\hline \multirow[t]{3}{*}{ Intrinsic coagulation disorders } & Imaging characteristics similar to anticoagulation \\
\hline & Multiple hematomas of different age and volume can coexist \\
\hline & Hemorrhage can occur after minor trauma \\
\hline Substance abuse (cocaine, & Ganglionic or lobar hemorrhages in young with or without \\
\hline amphetamine, ecstasy, PCP, & subarachnoid or intraventricular hemorrhages. Conventional \\
\hline decongestants and appetite suppressants) & angiography is necessary to rule out underlying vascular malformations \\
\hline \multirow[t]{3}{*}{ Infective endocarditis } & $\begin{array}{l}\text { Small and superficial hematomas secondary to formation of septic aneurysm } \\
\text { which is usually in distal arterial branches }\end{array}$ \\
\hline & Subarachnoid or intraventricular hemorrhages can occur \\
\hline & Conventional angiography is necessary to identify these small aneurysms \\
\hline \multirow[t]{2}{*}{ Vasculitis } & Combination of acute small ischemic and hemorrhagic lesions \\
\hline & $\begin{array}{l}\text { Characteristic beading of cerebral vasculature on MRA or conventional } \\
\text { angiography }\end{array}$ \\
\hline Moyamoya disease & $\begin{array}{l}\text { Hemorrhage in the presence of stenosis or occlusion at the terminal portion } \\
\text { of the internal carotid artery or the proximal portion of the anterior or middle } \\
\text { cerebral arteries and abnormal vascular networks in the vicinity of the occlusive } \\
\text { or stenotic areas }\end{array}$ \\
\hline Cerebral venous sinus thrombosis & $\begin{array}{l}\text { Hematomas typically in white matter or gray white junctions within close } \\
\text { proximity of major venous sinuses. It can often be temporal or involve } \\
\text { thalamus bilaterally. }\end{array}$ \\
\hline \multirow[t]{2}{*}{ Tumors } & Multiple stages of hematoma in the same lesion with debris-fluid level. \\
\hline & $\begin{array}{l}\text { Hematoma has persistent deoxyhemoglobin with absent hemosiderin and } \\
\text { shows inappropriate enhancement. Perihematoma edema and mass effect } \\
\text { can be seen in late hemorrhage }\end{array}$ \\
\hline \multirow[t]{2}{*}{ Head trauma } & $\begin{array}{l}\text { At bone brain or brain dura interfaces especially anterior or posterior temporal } \\
\text { lobes or anterior inferior frontal lobes }\end{array}$ \\
\hline & May be associated with subarachnoid, subdural or epidural hematomas \\
\hline Vascular anomalies & Discussed in Table 5 \\
\hline
\end{tabular}

DWI=Diffusion weighted image, $\mathrm{BBB}=$ blood brain barrier, $\mathrm{MRA}=$ magnetic resonance angiography. 

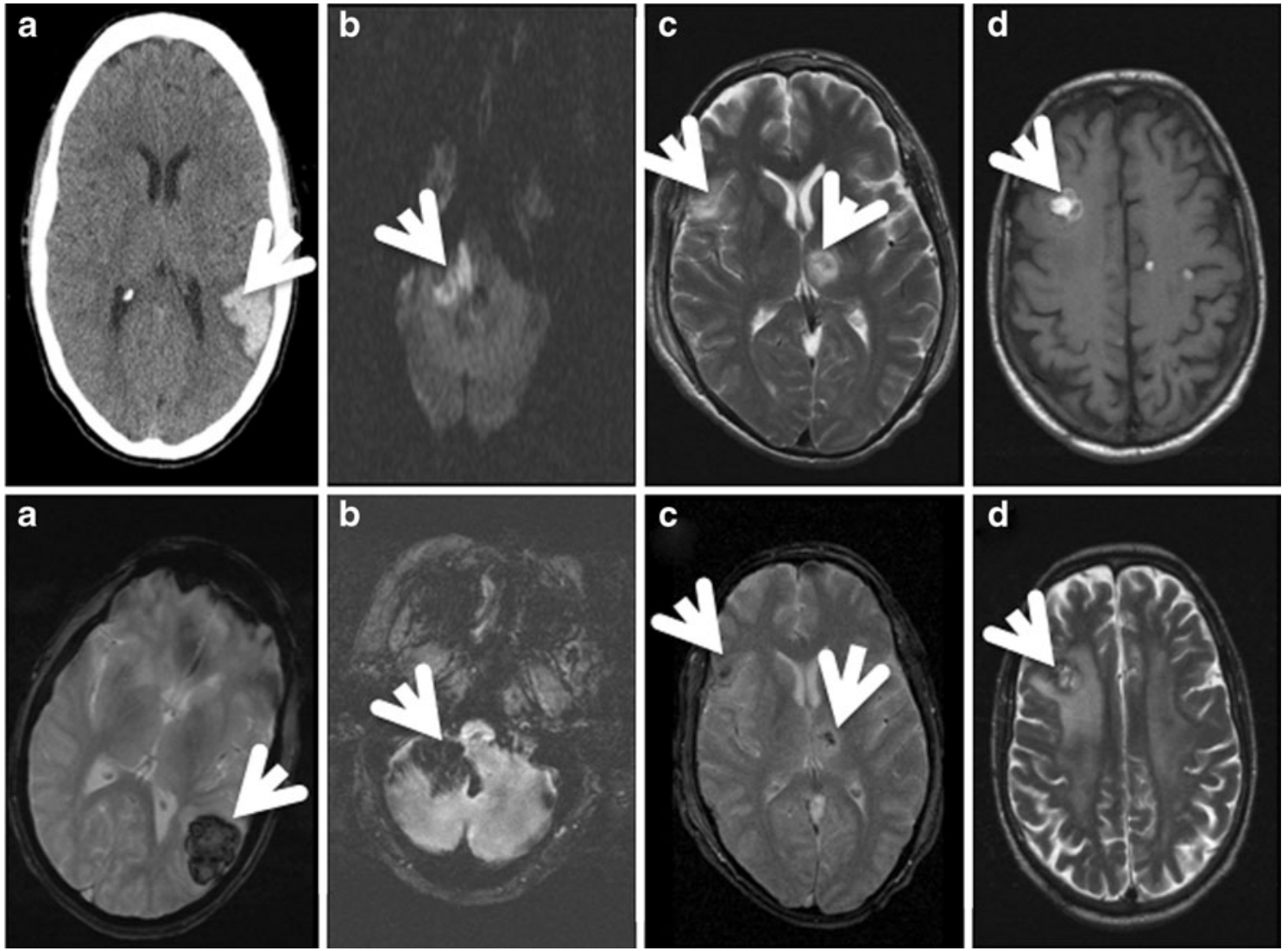

FIG. 2. Causes of secondary intraparenchymal hemorrhage (arrows). (a) Lobar hemorrhage (CT and GRE), (b) hemorrhagic infarction [diffusion weighted imaging (DWI) and GRE], (c) traumatic intraparenchymal hemorrhage [T2-weighted MRI (T2WI) and GRE], (d) intratumoral hemorrhage (postcontrast T1WI and T2WI). (High resolution version of this image is available in the electronic supplementary material.)

trauma, intracranial arteriovenous malformation (AVM), hemorrhagic tumor, dural AVM, blood dyscrasias or bleeding diatheses, amyloid angiopathy, moyamoya disease, or complications of pregnancy [5]. Traumatic brain injury is the most common cause of SAH. Typical locations for SAH after head trauma are the interpeduncular cistern, Sylvian fissure, or over the cerebral convexity [20]. The most common cause of atraumatic SAH is ruptured aneurysm which, if left untreated, has a $60-70 \%$ rate of mortality and morbidity [7]. $15 \%$ of patients with SAH do not have an underlying aneurysm or another etiology on angiography [5].

The evolution of SAH is different from that of other types of hemorrhages. SAH is a mixture of RBCs and other blood products with cerebral spinal fluid (CSF). The RBCs are either extravasated into the vascular system or phagocytized by leptomeningeal macrophages, resulting in the release of hemoglobin into the CSF [19]. The high oxygen content of SAH ensures slow degradation. This unique mixture of CSF and SAH has an impact on the appearance of the MRI scan. The elevated protein contents of bloody CSF causes a decrease in T1 signal and hyperintensity on T1-weighted images [21-23]. The susceptibility effect and $\mathrm{T} 2$ shortening may be absent in mild SAH as RBCs are resorbed before the formation of methemoglobin. For this reason, a CT scan is advocated for the early diagnosis of SAH [22, 24]. T2 shortening may occur in the case of massive SAH and in chronic and repeated SAHs secondary to superficial siderosis $[5$, 22]. Fluid-attenuated inversion recovery (FLAIR) is the most sensitive MRI pulse sequence for detecting SAH and is comparable to the CT scan in diagnosing acute SAH [25-30]. SAH appears hyperintense CSF on fluidattenuated inversion recovery images. The gradient recalled echo (GRE) technique can also be helpful in detecting SAH. SAH appears as a hypointense area surrounded by hyperintense subarachnoid spaces on the GRE MRI pulse sequence [19, 31, 32]. The newer 3dimensional CT angiography (CTA) and MR angiography (MRA) can facilitate the detection of very small aneurysms and are a good noninvasive alternative to digital subtraction angiography as a screening tool as well during the follow up after initial detection [33-35]. Detailed angiographic findings are beyond the scope of this review. Please refer to FIG. 3 for some examples of SAH with aneurysm rupture and trauma. FIG. 4 shows some examples of 3-dimensional CTA images of intracranial aneurysms. 

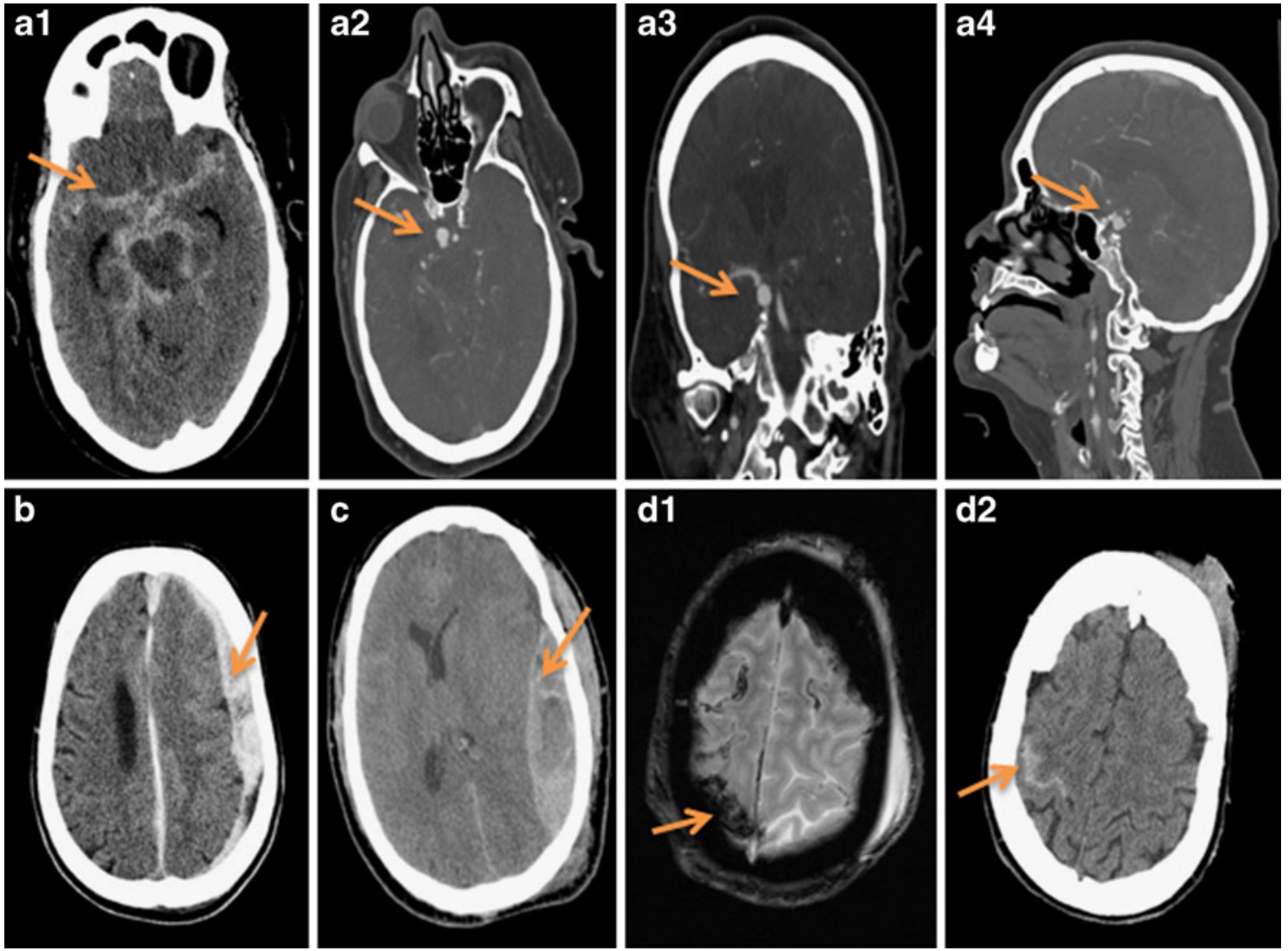

FIG. 3. Examples of subarachnoid, subdural, and epidural hematoma (arrows). (a1) Subarachnoid hemorrhage (CT), (a2, a3, a4) axial, coronal, and sagittal views of right posterior communicating artery aneurysm (CT angiography), respectively, (b) left subdural hemorrhage (CT), (c) left epidural hematoma (CT), (d1, d2) traumatic subarachnoid hemorrhage (CT and GRE). (High resolution version of this image is available in the electronic supplementary material.)

\section{Vascular malformation}

There are many vascular malformations that can be a potential cause of ICH. Vascular malformations are traditionally classified into four categories:
1. True AVMs

2. Capillary telangiectasias

3. Cavernous hemagiomas

4. Venous hemangiomas.
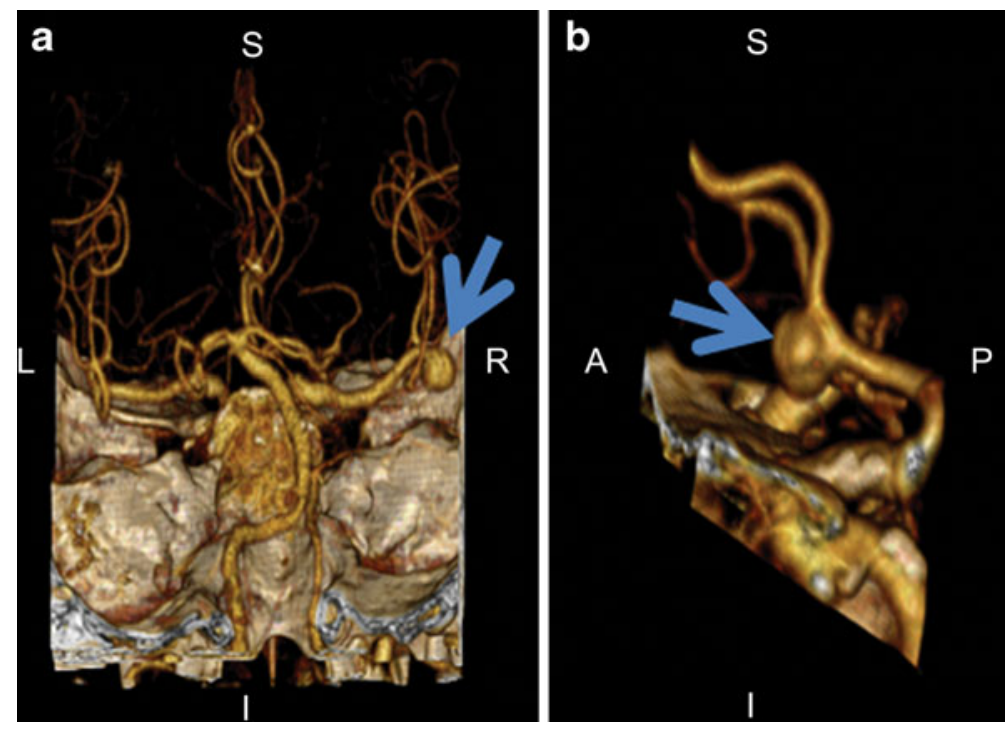

FIG. 4. 3-Dimensional CT angiographic images of intracranial aneurysms. (a) Right middle cerebral artery aneurysm (arrow), b anterior communicating artery aneurysm (arrow). $\mathrm{A}=$ Anterior, $\mathrm{P}=$ posterior, $\mathrm{S}=$ superior, $\mathrm{I}=$ inferior, $\mathrm{L}=\mathrm{left}, \mathrm{R}=$ right. (High resolution version of this image is available in the electronic supplementary material.) 
MRI is very sensitive to flow abnormalities in vascular structures. This property makes MRI the ideal tool to detect vascular malformations. MRI can sometimes pick up lesions that are not even detected by angiography. Table 5 describes the unique imaging characteristics of different types of vascular malformations.

\section{Subdural hematoma and epidural hematoma}

SDH can be traumatic or non traumatic. Nontraumatic SAH can be spontaneous without a precipitating cause, or it may be secondary to coagulopathy or antithrombotic therapy. These hemorrhages are most commonly seen along the cerebral convexities, the falx cerebri, and the tentorium cerebelli (FIG. 3) [19]. Like intraparenchymal hemorrhage, SDH has five distinct stages of evolution and, therefore, five appearances on MRI [24, 36]. Progression from one stage to another is slower because of the high vascularity of the dura, resulting in high oxygen tension and the slower degradation of hemoglobin. The major neuroimaging difference from intraparenchymal hemorrhage occurs in the chronic stage of $\mathrm{SDH}$ due to the formation of nonparamagnetic hemochromates. These are the product of continued oxidative denaturation of the methemoglobin. A hemosiderin rim is characteristically seen surrounding the SDH due to the absence of tissue macrophages.
EDHs usually occur after acute head trauma, and the clinical presentation might be delayed (FIG. 3). Arterial EDHs usually result from injury to the branches of the meningeal arteries, whereas venous EDHs may result from a tear in the dural venous sinuses. Venous EDHs are more commonly seen in children and can develop more slowly, with less acute symptoms, than arterial EDH [19]. EDHs evolve in manner similar to that of SDHs. EDHs are differentiated from SDH on the basis of their classic biconvexity versus medially concavity and on the basis of the intensity of the fibrous dura matter [19, 24]. No dilution with CSF occurs as EDH is separated from CSF by thick dura. A rapidly enlarging arterial EDH can cause a midline shift, culminating in herniation and possible secondary ischemia. Neuroimaging can be life saving in these cases [37].

\section{NEW IMAGING TECHNIQUES}

New imaging techniques have provided insight into the pathophysiology of ICH. Various imaging techniques are employed to study ongoing secondary neuronal injury in the perihematomal region, including positron emission tomography (PET), single photon emission computed tomography (SPECT), MR perfusion, and CT

Table 5. Neuroimaging Characteristics of Vascular Malformations [2, 5, 7$]$

\begin{tabular}{|c|c|}
\hline Vascular malformations & Neuroimaging characteristics \\
\hline True AVM & $\begin{array}{l}\text { CT: Enlarged tangled vessels in brain parenchyma with } \\
\text { curvilinear or speckled calcification } \\
\text { MR: Curvilinear flow void in most pulse sequences } \\
\text { MRA is useful in mapping the AVM. In lesions that have } \\
\text { high signal associated with adjacent hemorrhage, phase } \\
\text { contrast MRA is necessary to provide the best details of AVM } \\
\text { The angiographically cryptic AVM is often demonstrated by } \\
\text { MR. These lesions are known to contain a mixture of abnormal } \\
\text { vessels of various sizes, gliotic tissue, and hemosiderin. T1-weighted } \\
\text { MR images show a sharply demarcated focus of low signal, while } \\
\text { with T2-weighted images, the lesion center is bright, reflecting } \\
\text { prolongation of T2 expected in gliotic, hemorrhagic, or edematous } \\
\text { tissue. Flow in the AVM itself can be seen as a signal void on } \\
\text { T2-weighted images. http://www.med.harvard.edu/AANLIB/hem.html }\end{array}$ \\
\hline Cavernous hemangiomas & $\begin{array}{l}\text { CT: Calcified high density lesions that may enhance. } \\
\text { MR: Low intensity on T2WI and GRE (hemosiderin) surrounding } \\
\text { various circumscribed regions of hemorrhage (Hyperintense on } \\
\text { T1WI because of the presence of methemoglobin). As opposed to } \\
\text { tumors, there is a complete rim of hemosiderin surrounding the } \\
\text { cavernous hemangiomas. } \\
\text { Abuts ventricular or pial surfaces; also present in pons. }\end{array}$ \\
\hline Capillary telengiectasias & $\begin{array}{l}\text { Propensity for the pons, but may be seen in other places } \\
\text { Post contrast T1WI showed nodular enhancement. Isointense on } \\
\text { T2WI. GRE reveals hypointensity. }\end{array}$ \\
\hline Venous angiomas & $\begin{array}{l}\text { Linear structures with flow voids usually around ventricles with } \\
\text { transcerebral course and uniform umbrella shaped enhancement. }\end{array}$ \\
\hline
\end{tabular}

$\mathrm{AVM}=$ Arteriovenous malformation, $\mathrm{T} 1 / \mathrm{T} 2 \mathrm{WI}=\mathrm{T} 1 / \mathrm{T} 2$-weighted $\mathrm{MRI}$. 
perfusion. These newer techniques have demonstrated perihematomal regions of hypoperfusion and bioenergetic compromise, although frank perihematomal hypoperfusion that reaches classic ischemic thresholds does not occur [19, 38-48]. Specifically, the results of PET studies have not shown evidence of hypoxia or ischemia (i.e., normal oxygen extraction fraction and 18 F-fluoromisonidazole uptake) surrounding the intraparenchymal hemorrhage. Therefore, the most prevalent hypothesis to account for perihematomal hypoperfusion is secondary metabolic failure [19]. Several additional neuroimaging techniques, including diffusion tensor imaging, magnetic resonance spectroscopy, and near infrared spectroscopy, have shown immense potential [19]. Near infrared spectroscopy can potentially identify subdural and epidural hematomas in the field or at the bedside in patients with head trauma [49, 50]. Diffusion tensor imaging, by utilizing its property of visualizing white matter tracts, can be very helpful to understand the potential of motor recovery through the assessment of the integrity of the corticospinal tract in the acute, subacute, and chronic stages of intraparenchymal hemorrhage [51]. It also shows a characteristic pattern of tissue degeneration in hemorrhage secondary to amyloid angiopathy [52]. Preliminary clinical experience with recently introduced 320-row CT that enables dynamic CT angiography (4-dimensional CTA) of the entire intracranial circulation and whole-brain perfusion imaging indicates that 320-row CT is a technically robust procedure suitable for comprehensive neuroimaging of acute stroke patients. It can provide dynamic angiographic and perfusion data of the whole brain and can deliver additional diagnostic information not available by the standard CT scan [53]. Other potential goals of neuroimaging include imaging-guided therapy that targets specific stages of injury, use of high-strength magnets to detect micro-hemorrhages and cerebrovascular amyloid, and use of tissue probes and imaging biomarkers of inflammation, edema, and excitotoxicity [19].

\section{CONCLUSION}

Neuroimaging of ICH is a rapidly evolving field. It plays a critical role in the diagnosis and facilitates the localization, management, and prognostication. It also gives an insight into the mechanism of the injury. New techniques, including magnetic resonance spectroscopy and diffusion tensor imaging, are promising and will help us in understanding the dynamic pathophysiology of hemorrhage, its time course, and its recovery process. The use of real-time, high-field MRI with 3-dimensional imaging and high-resolution tissue probes can be helpful in establishing newer therapeutic options for acute ICH.

\section{REFERENCES}

1. Ropper AH, Adams RD, Victor M, Samuels MA. Adams and Victor's principles of neurology. 9th ed. New York: McGraw-Hill Medical; 2009.

2. Rabinstein AA, Resnick SJ. Practical neuroimaging in stroke : a case-based approach. Philadelphia: Saunders/Elsevier; 2009.

3. Report of the Joint Committee for Stroke Facilities. XII. Computed tomography in the management of cerebrovascular disease. Stroke 1975;6:103-107.

4. Kidwell CS, Chalela JA, Saver JL, et al. Comparison of MRI and $\mathrm{CT}$ for detection of acute intracerebral hemorrhage. JAMA 2004;292:1823-1830.

5. Yousem DM, Grossman RI. Neuroradiology : the requisites. 3rd ed. Philadelphia: Mosby/Elsevier; 2010.

6. Fiebach JB, Schellinger PD, Gass A, et al. Stroke magnetic resonance imaging is accurate in hyperacute intracerebral hemorrhage: a multicenter study on the validity of stroke imaging. Stroke 2004;35:502-506.

7. Atlas SW. Magnetic resonance imaging of the brain and spine. 4th ed. Philadelphia: Wolters Kluwer/Lippincott Williams \& Wilkins; 2009.

8. Alemany Ripoll M, Stenborg A, Sonninen P, Terent A, Raininko R. Detection and appearance of intraparenchymal haematomas of the brain at $1.5 \mathrm{~T}$ with spin-echo, FLAIR and GE sequences: poor relationship to the age of the haematoma. Neuroradiology 2004;46:435-443.

9. Huisman TA. Intracranial hemorrhage: ultrasound, CT and MRI findings. Eur Radiol 2005;15:434-440.

10. Osborn AG. Diagnostic neuroradiology. St. Louis: Mosby; 1994.

11. Stark DD, Bradley WG. Magnetic resonance imaging. 2nd ed. St. Louis: Mosby Year Book; 1992.

12. Bradley WG, Jr. MR appearance of hemorrhage in the brain. Radiology 1993;189:15-26.

13. Sudlow CL, Warlow CP. Comparable studies of the incidence of stroke and its pathological types: results from an international collaboration. International Stroke Incidence Collaboration. Stroke 1997;28:491-499.

14. Flaherty ML, Haverbusch M, Sekar P, et al. Long-term mortality after intracerebral hemorrhage. Neurology 2006;66:1182-1186.

15. Broderick J, Connolly S, Feldmann E, et al. Guidelines for the management of spontaneous intracerebral hemorrhage in adults: 2007 update: a guideline from the American Heart Association/ American Stroke Association Stroke Council, High Blood Pressure Research Council, and the Quality of Care and Outcomes in Research Interdisciplinary Working Group. Stroke 2007;38:20012023.

16. Kothari RU, Brott T, Broderick JP, et al. The ABCs of measuring intracerebral hemorrhage volumes. Stroke 1996;27:13041305.

17. Hemphill JC, 3rd, Bonovich DC, Besmertis L, Manley GT, Johnston SC. The ICH score: a simple, reliable grading scale for intracerebral hemorrhage. Stroke 2001;32:891-897.

18. Mohr JP. Stroke: pathophysiology, diagnosis, and management. 4th ed. Philadelphia: Churchill Livingstone; 2004.

19. Kidwell CS, Wintermark M. Imaging of intracranial haemorrhage. Lancet Neurol 2008;7:256-267.

20. Stuckey SL, Goh TD, Heffernan T, Rowan D. Hyperintensity in the subarachnoid space on FLAIR MRI. AJR Am J Roentgenol 2007;189:913-921.

21. Satoh S, Kadoya S. Magnetic resonance imaging of subarachnoid hemorrhage. Neuroradiology 1988;30:361-366.

22. Chakeres DW, Bryan RN. Acute subarachnoid hemorrhage: in vitro comparison of magnetic resonance and computed tomography. AJNR Am J Neuroradiol 1986;7:223-228.

23. Yoon HC, Lufkin RB, Vinuela F, Bentson J, Martin N, Wilson G. MR of acute subarachnoid hemorrhage. AJNR Am J Neuroradiol 1988;9:404-905.

24. Patel MR, Edelman RR, Warach S. Detection of hyperacute primary intraparenchymal hemorrhage by magnetic resonance imaging. Stroke 1996;27:2321-2324.

25. Atlas SW. MR imaging is highly sensitive for acute subarachnoid hemorrhage ... not! Radiology 1993;186:319-322; discussion 23. 
26. Hajnal JV, Bryant DJ, Kasuboski L, et al. Use of fluid attenuated inversion recovery (FLAIR) pulse sequences in MRI of the brain. J Comput Assist Tomogr 1992;16:841-844.

27. Noguchi K, Ogawa $\mathrm{T}$, Seto $\mathrm{H}$, et al. Subacute and chronic subarachnoid hemorrhage: diagnosis with fluid-attenuated inversion-recovery MR imaging. Radiology 1997;203:257-262.

28. Mohamed M, Heasly DC, Yagmurlu B, Yousem DM. Fluidattenuated inversion recovery MR imaging and subarachnoid hemorrhage: not a panacea. AJNR Am J Neuroradiol 2004;25:545550 .

29. Noguchi K, Seto H, Kamisaki Y, Tomizawa G, Toyoshima S, Watanabe N. Comparison of fluid-attenuated inversion-recovery MR imaging with CT in a simulated model of acute subarachnoid hemorrhage. AJNR Am J Neuroradiol 2000;21:923-927.

30. Woodcock RJ, Jr., Short J, Do HM, Jensen ME, Kallmes DF. Imaging of acute subarachnoid hemorrhage with a fluid-attenuated inversion recovery sequence in an animal model: comparison with non-contrast-enhanced CT. AJNR Am J Neuroradiol 2001;22:16981703.

31. Fiebach JB, Schellinger PD, Geletneky K, et al. MRI in acute subarachnoid haemorrhage; findings with a standardised stroke protocol. Neuroradiology 2004;46:44-48.

32. Sohn $\mathrm{CH}$, Baik SK, Lee HJ, et al. MR imaging of hyperacute subarachnoid and intraventricular hemorrhage at $3 \mathrm{~T}$ : a preliminary report of gradient echo $\mathrm{T} 2 *$-weighted sequences. AJNR Am J Neuroradiol 2005;26:662-665.

33. Harrison MJ, Johnson BA, Gardner GM, Welling BG (1997) Preliminary results on the management of unruptured intracranial aneurysms with magnetic resonance angiography and computed tomographic angiography. Neurosurgery 1997;40:947-955; discussion 55-57.

34. Chen CY, Hsieh SC, Choi WM, Chiang PY, Chien JC, Chan WP. Computed tomography angiography in detection and characterization of ruptured anterior cerebral artery aneurysms at uncommon location for emergent surgical clipping. Clin Imaging 2006;30:87-93.

35. Villablanca JP, Jahan R, Hooshi P, et al. Detection and characterization of very small cerebral aneurysms by using $2 \mathrm{D}$ and $3 \mathrm{D}$ helical CT angiography. AJNR Am J Neuroradiol 2002;23:11871198.

36. Smith EE, Rosand J, Greenberg SM. Hemorrhagic stroke. Neuroimaging Clin N Am 2005;15:259-272, ix.

37. Gean AD. Imaging of head trauma. New York: Raven Press; 1994.

38. Siddique MS, Fernandes HM, Wooldridge TD, Fenwick JD, Slomka P, Mendelow AD. Reversible ischemia around intracerebral hemorrhage: a single-photon emission computerized tomography study. J Neurosurg 2002;96:736741.

39. Zazulia AR, Diringer MN, Videen TO, et al. Hypoperfusion without ischemia surrounding acute intracerebral hemorrhage. J Cereb Blood Flow Metab 2001;21:804-810.

40. Rosand J, Eskey C, Chang Y, Gonzalez RG, Greenberg SM, Koroshetz WJ. Dynamic single-section CT demonstrates reduced cerebral blood flow in acute intracerebral hemorrhage. Cerebrovasc Dis 2002;14:214-220.

41. Sills C, Villar-Cordova C, Pasteur W, et al. Demonstration of hypoperfusion surrounding intracerebral hematoma in humans. J Stroke Cerebrovasc Dis 1996;6:17-24.

42. Kidwell CS, Saver JL, Mattiello J, et al. Diffusion-perfusion MR evaluation of perihematomal injury in hyperacute intracerebral hemorrhage. Neurology 2001;57:1611-1617.

43. Fainardi E, Borrelli M, Saletti A, et al. Assessment of acute spontaneous intracerebral hematoma by CT perfusion imaging. J Neuroradiol 2005;32:333-336.

44. Butcher KS, Baird T, MacGregor L, Desmond P, Tress B, Davis S. Perihematomal edema in primary intracerebral hemorrhage is plasma derived. Stroke 2004;35:1879-1885.

45. Herweh C, Juttler E, Schellinger PD, et al. Evidence against a perihemorrhagic penumbra provided by perfusion computed tomography. Stroke 2007;38:2941-2947.

46. Qureshi AI, Wilson DA, Hanley DF, Traystman RJ. No evidence for an ischemic penumbra in massive experimental intracerebral hemorrhage. Neurology 1999;52:266-2672.

47. Hirano T, Read SJ, Abbott DF, et al. No evidence of hypoxic tissue on 18 F-fluoromisonidazole PET after intracerebral hemorrhage. Neurology 1999;53:2179-2182.

48. Schellinger PD, Fiebach JB, Hoffmann K, et al. Stroke MRI in intracerebral hemorrhage: is there a perihemorrhagic penumbra? Stroke 2003;34:1674-1679.

49. Kahraman S, Kayali H, Atabey C, Acar F, Gocmen S. The accuracy of near-infrared spectroscopy in detection of subdural and epidural hematomas. J Trauma 2006;61:1480-1483.

50. Kessel B, Jeroukhimov I, Ashkenazi I, et al. Early detection of lifethreatening intracranial haemorrhage using a portable near-infrared spectroscopy device. Injury 2007;38:1065-1068.

51. Cho SH, Kim DG, Kim DS, Kim YH, Lee CH, Jang SH. Motor outcome according to the integrity of the corticospinal tract determined by diffusion tensor tractography in the early stage of corona radiata infarct. Neurosci Lett 2007;426:123-127.

52. Salat DH, Smith EE, Tuch DS, et al. White matter alterations in cerebral amyloid angiopathy measured by diffusion tensor imaging. Stroke 2006;37:1759-1764.

53. Siebert E, Bohner G, Masuhr F, et al. Neuroimaging by 320-row CT: is there a diagnostic benefit or is it just another scanner? A retrospective evaluation of 60 consecutive acute neurological patients. Neurol Sci 2010 Oct 28 [Epub ahead of print].

54. Qureshi AI, Tuhrim S, Broderick JP, Batjer HH, Hondo H, Hanley DF. Spontaneous intracerebral hemorrhage. N Engl J Med 2001;344:1450-1460.

55. Qureshi AI, Mendelow AD, Hanley DF. Intracerebral haemorrhage. Lancet 2009;373:1632-1644.

56. Scott RM, Smith ER. Moyamoya disease and moyamoya syndrome. N Engl J Med 2009;360:1226-1237.

57. Gennarelli TA, Thibault LE. Biomechanics of acute subdural hematoma. J Trauma 1982;22:680-686. 